\title{
Effects related to dimensions of purchasing decision quality of vegetables and fruits at grocery stores in Slovenia
}

\author{
D. Grusovnik and C. Rozman \\ Department of Agricultural Economics, Faculty of Agriculture and Life Sciences, University of Maribor, Hoce, Slovenia
}

\begin{abstract}
Summary
The purpose of the study was to identify and analyze the effects leading to and from the dimensions of purchasing decision quality of vegetables, fruits, or both, at grocery stores in Slovenia. For the research a combination of online and paper-pencil surveys was carried out nationwide in Slovenia. As the research method the structural equation modeling was used. Brand/origin and color/size were identified as dimensions of a theoretical formative, second-order latent construct of the purchasing decision quality of vegetables, fruits or both at grocery stores in Slovenia. Therefore, domestic producers and managers of retailers should focus on creating strong and recognizable brands. Research focus was on the direct effects pointing to and from the identified dimensions. Those buyers who were purchasing more often, to them the dimensions of brand/origin and color/size were significantly more important. Purchases duration had a significant positive effect on the dimension of brand/origin, while the level of self-sufficiency from one's own garden or field had a negative effect on the dimension of brand/origin. Buyers, who had highly valued the dimension of brand/origin, had purchased perceived quality products that were significantly in higher price ranges. Also, buyers who had highly valued the dimension of brand/origin had higher shares of purchased domestic products. This study provides new guidelines for Slovenian producers, retailers, and suppliers of vegetables and fruits. The originality of this study is that it simultaneously analyzes the effects of purchasing frequency, purchases duration, and level of self-sufficiency from one's own garden or field.
\end{abstract}

\section{Keywords}

vegetables and fruits, purchasing decision quality, grocery stores, self-sufficiency, purchasing frequency, purchases duration

\section{Introduction}

An increasing number of people, because of the progress of urbanization and busy lifestyle, are buying fruits and vegetables primarily from grocery stores and do not grow their own. Some do not have time to grow their own crops, some might perceive that it is just too much work, and some might think that the time invested, cost of seeds, and everything required for the production, is not cost beneficial. Buyers also purchase certain foods at grocery stores that they cannot grow in their own gardens, especially tropical fruits

\section{Significance of this study}

What is already known on this subject?

- Purchasing decision quality dimensions of vegetables and fruits at grocery stores have been identified in past studies in regions all over the globe.

\section{What are the new findings?}

- Identified new impacts that are connected to the identified dimensions of purchasing decision quality of vegetables and fruits at grocery stores.

What is the expected impact on horticulture?

- In this study production and marketing guidelines for Slovenian domestic producers of vegetables and fruits are being formed.

or other exotic products. According to Olstad et al. (2017), supermarkets represent an important environment for influencing food selection and consumption. Olstad et al. (2017) also quote that most of the household food budget is spent in supermarkets, which gives them significant power and control over the global food supply. This power can be readily leveraged with prices and the type of products that are offered in a store (e.g., healthy, unprocessed food like fresh vegetables and fruits versus unhealthy, processed or even ultra-processed food) (Olstad et al., 2017).

Slovenian domestic producers are struggling to stay competitive with the lower prices and the economies of scale from foreign producers. The growth of vegetable and fruit imports in Slovenia is a sign that the grocery stores, as a source of vegetables and fruits, are continuously increasing in number. Poole and Baron (1996) identified that the main source of purchasing fruits for British buyers were supermarkets at $89 \%$, green-grocer shops at $34 \%$, and the local market, $15 \%$.

The research in this paper will try to discover the hidden information linked to the buyers of vegetables, fruits or both in Slovenia, and on behalf on that research, make valuable conclusions, that might help the domestic producers and retailers. The motivation is to better understand the buyers of vegetables, fruits or both in grocery stores. Also the research uniqueness is to focus only on the last three purchases to prevent guessing and get fresh and more objective data.

To obtain information about a purchase is difficult, because buyers quickly forget after the purchasing decision has been made. Therefore, exact information about the spending and the amounts being bought are almost impossible to obtain, unless you are at the site of the actual purchase. Based on the results, this paper will try to make logical and helpful conclusions using the remaining information available in the minds of buyers after their purchase. 
The research will concentrate on the purchasing decision quality of vegetables, fruits or both at grocery stores in Slovenia and is composed as follows: first, a detailed review of literature on the observed subject, and then, methodology, data sources, and results will be presented.

\section{Objective and past research}

In this section goals and some vital past research from different areas that is connected to the newly developed research model in this paper will be presented. Grocery stores in this research represent all the stores where vegetables, fruits or both can be purchased (markets, small stores, supermarkets, discounters, hypermarkets, etc.).

When observing the buyers of vegetables, fruits, or both at grocery stores in Slovenia, the goals of this study are:

1. To identify which dimensions and their corresponding attributes form the theoretical formative latent construct of the buyers' purchasing decision quality of vegetables, fruits, or both at grocery stores in Slovenia.

\section{Attributes of purchasing decision of vegetables and fruits}

Poole and Baron (1996) researched the quality attributes (external: physical and perceived) of oranges and mandarins in the United Kingdom. The order from the most important attribute to the least important was the following: 1. juiciness, 2. skin quality, 3. sweetness, 4. texture, 5. price, 6. color, 7. ease of peeling, 8. no pips, 9. size, and 10. packaging. They also found out that consumers relied heavily on past experience in deciding which fruit to buy. Consumer satisfaction is vested largely in quality attributes that cannot be identified before consumption. Thus, purchasing decisions are not consistent with consumer preferences and satisfaction. As seen in the mentioned survey, some of the attributes differ in accordance with which fruit or vegetable is being researched; and some of the other attributes could be applied to all fruits or vegetables (e.g., texture, price, color, size, and packaging).

Grunert (2005) developed The Total Quality Food Model that proposes a vertical and horizontal dimension for food quality perception can analysis. The horizontal dimension takes up well-known distinction between search, experience and credence qualities and its implications for consumers ability to assess quality before purchase, after purchase, or not at all, and the implications this has for the basis on which consumers will infer quality given the information to hand. The vertical dimensions deals with how the consumers infer quality from a variety of signals or cues, and with how consumers find out which properties of food products are desirable by linking them to basic motivators of human behavior.

Peneau et al. (2006) state that consumers' attitudes towards the purchase of a fruit is governed, to a great extent, by the importance they place in the sensory and non-sensory attributes of the fruit (Qing et al., 2012). According to Rozin et al. (1999), sensory attributes generally relate to consumers' perception of the appearance, texture, and flavor of the fruit, while non-sensory attributes relate to the location, brand, time, and handling of the fruit (Qing et al., 2012). A decisive attribute for the consumers' choice of fruits and vegetables is obviously freshness (Ragaert et al., 2004; Peneau et al., 2009; Qing et al., 2012).

Gao et al. (2014) conducted a survey on French consumers of citrus fruits. They measured the sensory attributes and the extrinsic attributes (country of origin, brand, and price) of citrus fruits. Their results showed that the extrinsic attri- butes (except price) were less important than sensory attributes. Gao et al. $(2011,2014)$ identified the attributes were consistent with their past research which demonstrated that freshness, flavor, appearance, and juiciness are the most important; and seeds and packaging, the least important attributes of citrus fruits. Among extrinsic attributes, country of origin was ranked as second most important, after price.

Saucede et al. (2014) analyzed the factors influencing a vegetable and fruit department's store performance. The two identified factors were: adequate marketing (assortment, promotion, thematisation, product presentation techniques, display, space allocation, and organization) and department upkeep (presentation and cleanliness, consistent and homogenous quality, and absence of shortfalls). Although, this is a different perspective compared to this research, promotion, cleanliness, quality, presentation, assortment, and absence of shortfalls could all be applied to the research.

Hsu et al. (2017) identified four dimensions that influence the vegetable purchasing decision of buyers in the Chinese cities of Taipei and Shanghai. In Taipei, these dimensions and the attributes they contained were ordered from the most important to the least important in the following way: 1. quality (appearance, nutrition, residuals); 2 . selection (convenient location, seasonal vegetables, variety in selection); 3. origin labeling (country of origin, brand, package); and 4. promotion (price mark down, reasonable pricing). The authors stated that further research was needed to examine the casual relationship between income and information needed in vegetable purchasing decisions. Olstad et al. (2017) also identified price mark down as an important attribute of vegetable and fruit purchasing decisions. In their study, participants (women in Melbourne, Australia) who received $20 \%$ discounts on all fresh vegetables and fruits were approximately twice as likely to report having increased proportionate purchases of vegetables and fruits. Waterlander et al. (2012) also proved, with an experiment in a web-based supermarket, that a $25 \%$ discount on fruits and vegetables was significantly associated with their higher total purchases. In connection with the convenient location, Thornton et al. (2012) proved, when researching vegetable and fruit consumption, that there was a positive connection between the stores within the 0.4 kilometer home radius (convenient location) and people without a car.

2. Do higher levels of self-sufficiency from one's own garden or field have a significant negative effect on purchasing frequency and purchasing duration (average time spent in the vegetable and fruit department)? Do those who purchase more often, really have shorter purchases durations? The level of self-sufficiency from one's own garden or field indicates how much food grows a person on his own, compared to how much he procures from elsewhere. The concept of a person's self-sufficiency is important because of the possible differences in purchasing decision quality of vegetables and fruits.

3. To analyze the effect of the level of self-sufficiency from one's own garden or field, purchasing frequency, and purchase duration, on the dimensions of purchasing decision quality of vegetables, fruits, or both at grocery stores. For instance, do buyers who cover a larger share of their needs with their own grown crops than those who have lower levels of self-sufficiency, at the same time also value more the identified dimensions of 
quality of purchasing decisions of vegetables, fruits, or both at grocery stores?

\section{Purchasing frequency}

Also, the interest of this paper is the purchasing frequency and its relationship with the dimensions of purchasing decision quality of vegetables, fruits or both at grocery stores. Calvo-Porral and Levy-Mangin (2016) discovered that satisfaction and loyalty toward specialty food stores are strongly influenced by the consumer purchasing frequency of specialty food products. Their findings also support the moderating role of purchasing frequency on the relationship between the store service and satisfaction. Poole and Baron (1996), in the United Kingdom, found out that different fruits had different purchasing frequencies. Compared with non-citrus fruits (apples and bananas), oranges and mandarins were purchased less frequently.

4. To find the statistically significant effects that the dimensions of purchasing decision quality of vegetables, fruits, or both at grocery stores have on the following selected purchases outcomes: price level of purchased, perceived quality (very good) products, share of purchased vegetables versus fruits, and share of purchased domestic products.

\section{Price level of purchased quality products and product origin}

An important area of the research will also be the price level of purchased, perceived quality products (measured in this research for the past three purchases) that is similar to the concept of willingness to pay (future purchases). Research articles on the relation between origin and willingness to pay are also in focus. Gao et al. (2014) identified that for French consumers, the price of citrus products was, on the one hand, not statistically significant when correlated to the country of origin, but on the other hand, willingness to pay had a statistically significant positive effect on the variable of country of origin (the exceptions were Turkish products). Participants concerned about the country of origin stated that they were willing to pay more for oranges from France, Spain, Turkey, and Florida; and even more for grapefruit from France, Turkey, Florida, and the US. But they intended to pay more for mandarins from France only.

5. Do the price levels of purchased, perceived quality products and the share of purchased vegetables versus fruits, have a positive effect on the share of purchased domestic products?

6. Determine if there are any statistically significant effects that demographics (gender, age, level of education, household income, and household size) have on the endogenous (dependent) variables in the research model.

\section{Methodology}

\section{Data}

For the purpose of this research, a combination of an online and a paper-pencil survey was conducted in October of 2017 (respondents from all the regions in Slovenia are represented). 229 respondents fully completed the survey (no missing data). Purchasing decision quality of vegetables, fruits, or both at grocery stores, was measured with 13 ques- tions. The research model will be calculated with structural equation modeling (SEM). According to Kline (2011), a typical sample size where structural equation modeling (SEM) is used in research is about 200 respondents. To obtain the final structure of the questionnaire, a pretest was performed to test the data of answers for normal distribution. Durian and Tucci (2013) used in their vegetable consumption research also a fairly small sample size of 250 respondents. For the basis of the study, 11 out of the final 13 attributes used in this survey were from the Hsu et al. (2017) study. The 13 used attributes were: country of origin, brand, packaging, convenient location, seasonal vegetables, variety in selection, color, appropriate size, nutrition, freshness, residuals, price mark down, and reasonable prices. Except freshness (Ragaert et al., 2004; Peneau et al., 2009; Qing et al., 2012), appropriate size and color (Poole and Baron, 1996), all the attributes were used by Hsu et al. (2017). 11 questions of the attributes were measured on a 5-point Likert scale (from 1 - strongly disagree to 5 - strongly agree). Respondents were asked to answer the following question: "The selected attribute was very important to us in the last three purchases." Two remaining questions of the attributes had 5 ordinal levels that were not measured on a Likert scale (variables: price mark down and reasonable prices). The more important the attribute was to the buyers, the higher their purchasing decision quality was. All the questions for the dependent and demographic variables (except gender) were measured on an ordinal scale (different sized by number of levels).

The novelty of this survey is that it is focused specifically on the buyers' last three purchases (purchases that the buyers actually executed and still exactly remembered). The attributes were adopted from other authors and are not a novelty. The main novelty of this research is the research model and the combination of the variables that it incorporates. The limitations of this study are the number participants and the number of questions that could be asked. If more questions could be asked, the Cronbach's alpha values could perhaps be stronger.

\section{Sample description}

With respect to the demographics, women were slightly in the majority with $57 \%$ (Table 1 ). The largest age group was $36-45$ years $(26 \%)$, followed by $26-35$ years $(23 \%)$, and then 46-55 years (21\%). Because it was an internet survey, the younger groups were expected to be more represented. Younger people are those who are noticeably more familiar with the internet. With respect to education level, those with college education dominated. The largest group, with 30\%, was the level V. (high schools like gymnasiums), followed with $22 \%$ percent by level VII., (master's degrees), then with $18 \%$, level VI. (bachelor degrees). Everything with level VI. and above is college education (the missing levels are presented in Table 1). Households with a monthly income of $€ 301-1,000$ were the highest, with $22 \%$, followed with $17 \%$ by households with a monthly income of $€ 2,001-2,500$, and then with $17 \%$ by households with a monthly income of $€ 1,501-2,000$. All the income classes were successfully attracted (low, middle, high). $€ 300$ is the approximate border for singles who are unemployed and receive social welfare, for pensioners whose pensions do not exceed this limit, and for students who received a scholarship or are working over a student service and do not exceed this limit (the missing households incomes are presented in Table 1). 3-member households were with $26 \%$ the most represented, followed with $23 \%$ by 4 -member households, and then followed 
TABLE 1. Demographics of respondents.

\begin{tabular}{|c|c|c|c|c|c|}
\hline \multicolumn{2}{|c|}{ Respondents demographics } & \multicolumn{4}{|c|}{$N=229$} \\
\hline Group & Number & $\%$ & Group & Number & $\%$ \\
\hline \multicolumn{6}{|c|}{ Gender } \\
\hline Male & 98 & 43 & Female & 131 & 57 \\
\hline \multicolumn{6}{|c|}{ Age } \\
\hline $0-25$ & 24 & 10 & $46-55$ & 48 & 21 \\
\hline $26-35$ & 52 & 23 & $55-65$ & 42 & 18 \\
\hline $36-45$ & 59 & 26 & $\geq 66$ & 4 & 2 \\
\hline \multicolumn{6}{|c|}{ Level of education (Slovenian classification) } \\
\hline I. & 1 & 0 & VI.-BA & 40 & 18 \\
\hline II.-PS & 5 & 2 & VII.-MA & 50 & 22 \\
\hline III. & 6 & 3 & VIII/1.-MSc & 22 & 10 \\
\hline IV.-SS & 32 & 14 & VIII/2.-PhD & 5 & 2 \\
\hline V. & 68 & 30 & & & \\
\hline \multicolumn{6}{|c|}{ Household income (€ per month) } \\
\hline$\leq 300$ & 13 & 6 & $3001-3500$ & 13 & 6 \\
\hline $301-1000$ & 51 & 22 & $3501-4000$ & 12 & 5 \\
\hline $1001-1500$ & 38 & 17 & $4001-4500$ & 7 & 3 \\
\hline $1501-2000$ & 31 & 14 & $4501-5000$ & 5 & 2 \\
\hline $2001-2500$ & 40 & 17 & $\geq 5001$ & 4 & 2 \\
\hline $2501-3000$ & 15 & 7 & & & \\
\hline \multicolumn{6}{|c|}{ Household size (number of members) } \\
\hline 1-member & 32 & 14 & 4-member & 53 & 23 \\
\hline 2-member & 54 & 24 & 5-member & 20 & 9 \\
\hline 3-member & 59 & 26 & $\geq 6$-member & 11 & 5 \\
\hline
\end{tabular}

Notes: PS - Primary school, SS - Secondary school, BA - Bachelor, MA - Master's degree, MSc - Master of Science, PhD - Doctors degree.

Source: Own research.

with $14 \%$ by the 1 -member households. All students were counted as 1-member households (the missing households are presented in Table 1). The most representative group in relation to self-sufficiency from their own garden was with $27 \%$ of the respondents, the group whose production covered $76 \%$ or more of their needs. Other groups in relation to the percentage of self-sufficiency were: $26-50 \%$ of the needs were covered (20\% of the respondents), $1-25 \%$ (20\%), 51-75\% (19\%), and they bought everything (14\% of the respondents).

\section{Exploratory factor analysis}

An exploratory factor analysis (EFA) was performed in the statistical program, SPSS 22, to find out which factors or dimensions could potentially form the theoretical formative latent construct of the purchasing decision quality of vegetables, fruits, or both at grocery stores (Table 1). For variables to be normally distributed, the skewness and kurtosis coefficients must be in the range of \pm 2.00 . All 13 variables with which the EFA was started were normally distributed. Also, all the variables used later in the research model were normally distributed. The normal distribution of used endogenous variables is a required condition for a valid structural equation model (SEM) (Kline, 2012; Jackson et al., 2005). With a size of 0.318 , the correlation coefficient in the factor matrix was noticeable. The factors of brand/origin and color/size explained $46.9 \%$ of the total explained variance. $46.9 \%$ is close to $50 \%$, which is tolerable (Streiner, 1994). For the EFA, the maximum likelihood (ML) method with promax rotation was used. Promax rotation is suitable when the factors are noticeably correlating with each other with a correlation coefficient that is above 0.3 . The correlation coefficient of the obtained factors was 0.318. The ML method is also a requirement when, later, the program, AMOS, will be used, which uses the exact same method.

The first factor of brand/origin (included variables: brand, origin, packaging, and nutrition) explained $31.3 \%$ of the explained variance and had the Cronbach's alpha coefficient of 0.734 , which indicates a highly reliable scale (Hinton et al., 2004). The second factor of color/size (included variables: color and size) explained $15.5 \%$ of the explained variance and had the Cronbach's alpha coefficient of 0.662 . The value of 0.662 indicates a moderately reliable scale (Hinton et al., 2004). According to Hinton et al. (2004), a Cronbach's alpha coefficient in the range of $0.5-0.7$ shows moderate reliability. During the EFA process the following attributes were eliminated: convenient location, seasonal vegetables, variety in selection, freshness, residuals, price mark down and reasonable prices. The KMO (Kaiser-Meier-Olkin) measure of sampling adequacy was 0.715 , above the required 0.7 mark (Lloret et al., 2017), and the Bartlett's test of sphericity was statistically significant as required, at $p<0.001$ level. The KMO measure and the Bartlett's test confirmed that our data was acceptable for the EFA. The chi-square $\left(\chi^{2}\right)$ or goodness of fit was statistically insignificant $(p>0.05)$, which meant that the null hypothesis could be rejected, that there is no significant difference between the observed and the expected values. According to all the presented data, the measurement model was good.

\section{Theoretical construct validation}

The purchasing decision quality of vegetables, fruits, or 


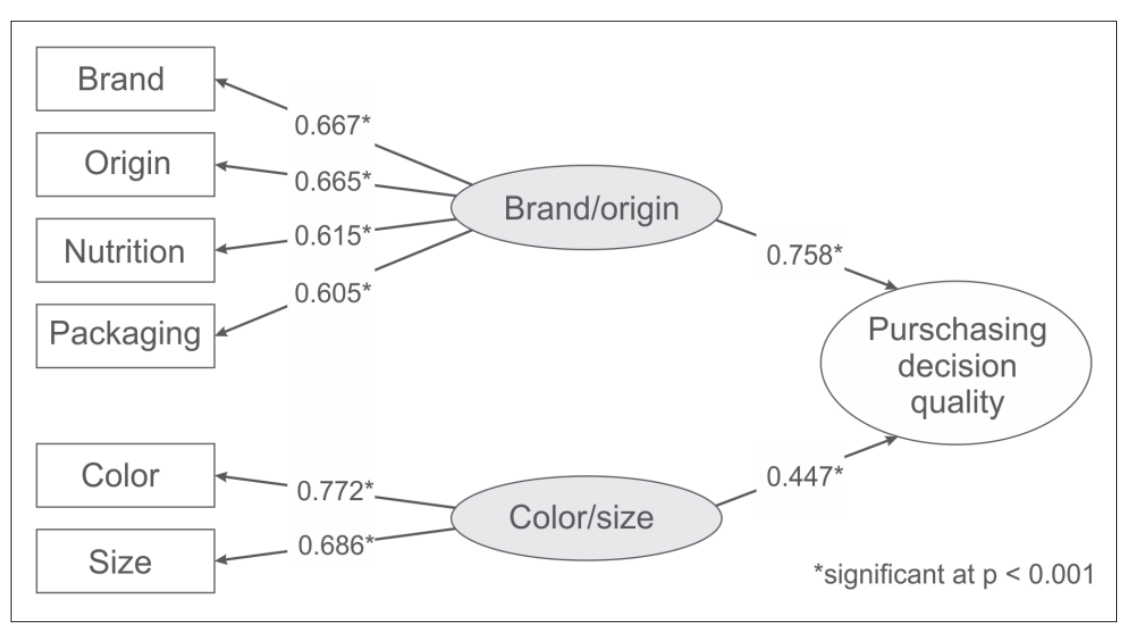

FIGURE 1. Validity of latent construct of purchasing decision quality. both at grocery stores is a formative $2^{\text {nd }}$ order latent construct. The formative $2^{\text {nd }}$ order construct contains two reflective $1^{\text {st }}$ order latent factors. A confirmative factor analysis (CFA) was conducted. In this phase of the process SmartPLS was used instead of AMOS because it can process formative latent variables. The validity of reflective latent variables is tested through the following: sufficiently-sized outer loadings, composite reliability (CR), average variance extracted (AVE), and Cronbach's alpha. To obtain the outer loadings and weights, the "factor consistent PLS algorithm" function was executed in SmartPLS 3 (Ringle et al., 2015), which is used when latent variables are present in the model. To run the analysis, all the reflective variables of the dimensions needed, also, to be reflectively loaded on the latent variable of purchasing decision quality. The outer loadings (Figure 1) of the dimension of brand/origin were the following: brand (0.677), origin (0.665), nutrition (0.615), and packaging (0.605). And the outer loadings of the dimension of color/ size were the following: color (0.722) and appropriate size $(0.686)$. To obtain the statistical significance of the loadings and weights, the "factor consistent bootstrapping" function was executed. All outer loadings were statistically significant $(p<0.001)$. According to Comrey and Lee (2007) there is the following loading strength classification: good (0.55-0.63), very good $(0.63-0.71)$, excellent $(>0.71)$. Only one loading of the latent constructs was categorized as good; all the others were, at least, very good.

Composite reliability (CR) was used to evaluate reliability and average variance extracted (AVE) for convergent validity of the latent constructs. Except the AVE of both dimensions of purchasing decision quality, the remaining measures were above the recommended cut-off levels of 0.6 for CR and 0.5 for AVE (Fornell and Larcker, 1981). The AVE of the dimension of color/size was 0.497 , close to 0.5 , while the dimension of brand/origin had an AVE of 0.411. The CR of dimension of brand/origin was 0.736 , while the dimension of color/size

TABLE 2. Factor loadings and reliability of the measurement model.

\begin{tabular}{|c|c|c|c|c|}
\hline Factor & Variables & $\begin{array}{l}\text { Statements related to purchasing decision of vegetables, fruits or both at } \\
\text { grocery stores (for the last } 3 \text { purchases) }\end{array}$ & $\begin{array}{l}\text { Factor } 1 \\
\text { loadings }\end{array}$ & $\begin{array}{l}\text { Factor } 2 \\
\text { loadings }\end{array}$ \\
\hline \multirow[t]{4}{*}{ Brand/origin } & Brand & $\begin{array}{l}\text { The brand was important to us (e.g., Lust, Chiquita, name of producer...). We } \\
\text { know the producers and brands for the products we purchased. }\end{array}$ & 0.803 & \\
\hline & Origin & $\begin{array}{l}\text { For purchased products, we know the country of origin and that was important } \\
\text { to us. }\end{array}$ & 0.702 & \\
\hline & Packaging & $\begin{array}{l}\text { It was important how the products were packaged (e.g., packaging with } \\
\text { breathing holes, waxed products, and plastic boxes or similar). }\end{array}$ & 0.538 & \\
\hline & Nutrition & $\begin{array}{l}\text { In our purchases we were aware of the desired nutrition substances that the } \\
\text { products contained, and we were actively searching for them (e.g., vitamins, } \\
\text { minerals, fibers, antioxidants and other nutritional substances). }\end{array}$ & 0.467 & \\
\hline \multicolumn{5}{|c|}{ Cronbach's alpha $=0.734$} \\
\hline \multicolumn{5}{|c|}{$\%$ of variance $=31.3 \%$} \\
\hline \multirow[t]{2}{*}{ Color/size } & Color & $\begin{array}{l}\text { The color of purchased products was important to us, and we chose the best } \\
\text { what was being offered at the grocery stores. }\end{array}$ & & 0.907 \\
\hline & Size & $\begin{array}{l}\text { We looked at the size of the products, and it was important to us (some like it } \\
\text { thick, some thin, some small, some something in the middle; you purchased the } \\
\text { size that was acceptable to you). }\end{array}$ & & 0.520 \\
\hline \multicolumn{5}{|c|}{ Cronbach's alpha $=0.662$} \\
\hline \multicolumn{5}{|c|}{$\%$ of variance $=15.5 \%$} \\
\hline \multicolumn{5}{|c|}{$\begin{array}{c}\text { KMO (Kaiser-Meier-Olkin) measure of sampling adequacy }=0.715 \text {. } \\
\text { Chi-square }\left(X^{2}\right) \text { or goodness of fit was statistically insignificant }(p=0.057) \text {. } \\
\text { Total variance explained }=46.9 \% \text {. }\end{array}$} \\
\hline
\end{tabular}


had a CR of 0.663. An AVE of 0.411 can be accepted, because Fornel and Larcker (1981) state that if AVE is less than 0.5, but composite reliability is higher than 0.6 , the convergent validity of the construct is still adequate. AVE is a strict measure of convergent validity. Malhotra and Dash (2011) also note that AVE is a more conservative measure than CR. On the basis of CR alone, the researcher may conclude that the convergent validity of the construct is adequate, even though more than $50 \%$ of the variance is due to error (Malhotra and Dash, 2011). The Cronbach's alpha coefficient of the dimension brand/origin was 0.734 , and of the dimension of color/ size, it was 0.663 . The Cronbach's alpha coefficients of the reflective latent variables in the exploratory factor analysis (EFA) and in the theoretical formative model were of identical sizes.

The validity of formative latent variables is tested through the following: with the statistically significant positive outer weights and with existence of low multicollinearity (measured with variance inflation factors - VIF). The weights (Figure 1) on the paths from both dimensions to the construct of purchasing decision quality were positive and statistically significant (brand/origin $=0.758$, color $/$ size $=0.447$, both significant at $p<0.001$ ). All the VIF coefficients of the predictor variables were smaller than 1.7 (required: <3.0). All the presented data confirm that the dimensions of brand/origin and color/size are part of the theoretical formative $2^{\text {nd }}$ order latent construct of the purchasing decision quality of vegetables, fruits, or both at grocery stores.

\section{Structural equation modeling (SEM)}

After the theoretical construct validation in program AMOS 22, a structural equation model with all the paths was built (Figure 2). In this research model, direct effects pointing to and from the dimensions were planned to be measured, because so many more useful specific results for domestic vegetable and fruit producers could be outlined. The program, AMOS, was used for SEM path analysis instead of SmartPLS, because it provides modification indices and a larger variety of model fit coefficients.

The process of improving the model fit of SEM is visible in the $2^{\text {nd }}$ and $3^{\text {rd }}$ column (from the left) in Table 3. Covariance arrows have been inserted between the variables of the
TABLE 3. Model fit coefficients of SEM, before and after modification indices.

\begin{tabular}{lcc}
\hline Model fit coefficient & \multicolumn{2}{c}{ SEM } \\
\cline { 2 - 3 } requirements & 1 $^{\text {st }}$ attempt & Optimized \\
\hline$X^{2} / \mathrm{df}$ & $455.936 / 88$ & $102.956 / 75$ \\
$X^{2}, \mathrm{p}>0.05$ & 0.000 & 0.018 \\
$\mathrm{CMIN} / \mathrm{df}<5$ & 5.181 & $1.373^{*}$ \\
$\mathrm{GFI}>0.9$ & 0.821 & $0.954^{*}$ \\
$\mathrm{CFI}>0.9$ & 0.613 & $0.971^{*}$ \\
$\mathrm{PCFI}>0.5$ & 0.353 & 0.476 \\
$\mathrm{PCLOSE}>0.05$ & 0.000 & $0.792^{*}$ \\
RMSE $<0.1$ & 0.135 & $0.040^{*}$ \\
\hline
\end{tabular}

Notes: *coefficient is in the required range; $X^{2} / \mathrm{df}-$ Chi-square/degrees of freedom; CMIN/df - Minimum discrepancy; GFI - Goodness of fit index; CFI - Bentler comparative fit index; PCFI - Parsimony-adjusted CFI; PCLOSE - $p$ of close fit; RMSE - Root mean square error of approximation.

same order in accordance to the program modification indices. Arrows of covariances can only be applied between the variables of the same order in a SEM model. The $p$-value of Chi-square could not be further improved to become statistically insignificant, and the reasons are the following: group size, characteristic of the group, and the complexity of the research model (high number of variables and paths). Also, the PCFI coefficient (PCFI - Parsimony-adjusted CFI; CFI Bentler Comparative Fit Index) was with 0.476 , just below the required value of 0.5 . According to the results, the model fit for SEM was adequate.

The determination coefficient $\left(\mathrm{R}^{2}\right)$ is the proportion of the variance in the dependent variable (in this research, the endogenous variables) that is predicted from the independent variable(s) (in this research, the exogenous variables). According to Cohen (1992), $\mathrm{R}^{2}$ of endogenous latent variables with values of 0.12 or below are indicated as weak, between 0.13 and 0.25 , are indicated as moderate, and 0.26 or above are indicated as substantial (for $\mathrm{R}^{2}$ results see Figure 2). The low $R^{2}(0.074)$ of share of vegetables versus fruits was not problematic, because there were no statistically significant paths which would lead to it (Figure 2). The $\mathrm{R}^{2}$ value of pur-

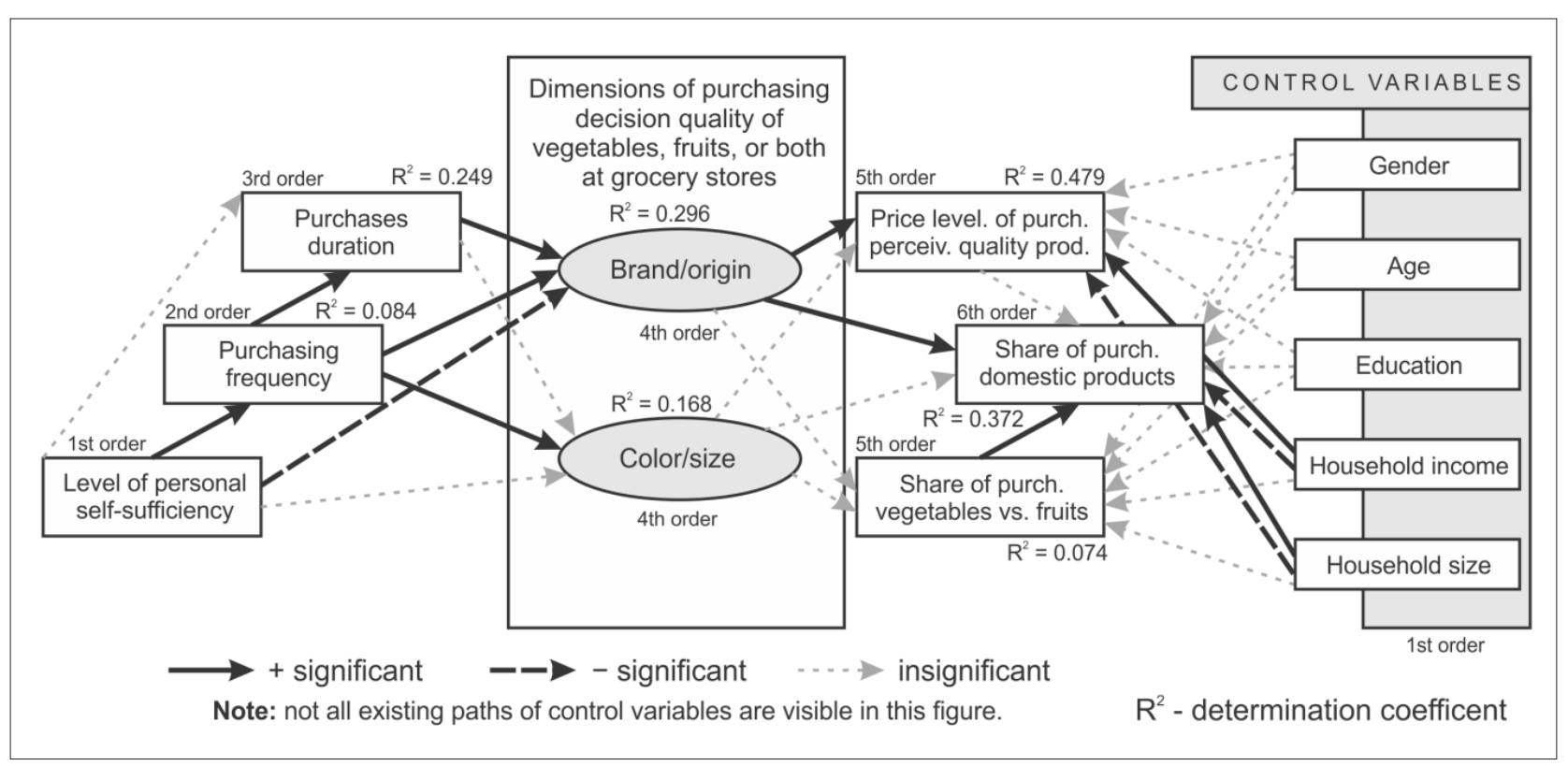

FIGURE 2. Research model. 
chasing frequency was indicated as weak, but with 0.084 , it was far from being zero. Because of the identified low $\mathrm{R}^{2}$ of purchasing frequency, their significance $(0.95$ level of confidence) was being calculated with the following formula:

$$
t_{r}=\frac{r \sqrt{n-2}}{\sqrt{1-r^{2}}}(\text { Louangrath, 2014). }
$$

If the $t_{r}$ (significance of the $R^{2}$ ) is above 1.64, then the SEM model produces significant results. The $t_{\mathrm{r}}$ in the SEM model for the purchasing frequency was with 4.56 above the required value of 1.64, which indicates that the model produces significant results; purchasing frequency:

$$
\mathrm{t}_{\mathrm{r}}=\frac{0.289 \sqrt{229-2}}{\sqrt{1-0.084}}=4.56 ;
$$

\section{( 0.289 in the equation is the square root of $\mathrm{R}^{2}$ ).}

As a control measure, the exact same SEM model was built in SmartPLS and, in relation to path significance, there were no differences compared to AMOS. Gender as a binary variable was not included in the SmartPLS model. Also, the model fit in SmartPLS was acceptable (Standardized Root Mean Square Residual: SRMR $=0.060$, recommended $<0.08$; Normed Fit index: NFI $=0.919$, recommended $>0.9$ ).

\section{Results}

\section{Effects on endogenous variables in the SEM model}

The majority of the results of the path analysis are also visible in Figure 2. The level of self-sufficiency from one's own garden or field had a statistically significant positive effect on purchasing frequency, which is encouraging information for the producers and retailers, because owning a garden or field does not negatively affect how often someone purchases vegetables, fruits, or both, at grocery stores (Table 4). It seems that purchasing frequency is a personal preference, going above what someone has at home at his free disposal, and is also probably dependent on other so- cioeconomic factors (for example, age and household size, which will be discussed more in detail later in this paper). Purchasing frequency has a statistically significant positive effect on purchase duration. One of the possible reasons for the last statement could be that people who have, at the same time, higher levels of self-sufficiency and a high purchasing frequency, then those people are more demanding or just looking for information (assumption is based on the path significances in the SEM model).

The level of self-sufficiency from one's own garden or field had a statistically significant negative effect on the dimension of brand/origin. Perhaps, people with higher levels of self-sufficiency make more use of their observations from the home-grown products and compare them with products at grocery stores, and the brand and origin loses for them on importance. One would also expect that buyers who own a garden or field would be more critical about the size and color of products, but that was not true in the case of this survey. One of the core reasons could be that they know how hard it is to grow quality vegetables or fruits, so their expectations were consequently lower positioned. To buyers with higher purchasing frequencies, the dimensions of brand/origin and color/size were statistically significantly more important. That is expected, because buyers who value the dimensions of brand/origin and color/size more, need to purchase more often to make sure that they can gather more information and build on their decision quality experience. In the purchases, they, more often, try to gather useful information and compare more products in order to be better focused in their next purchases. Buyers probably not only try to gather more visual and text information, but also try to process and remember them long-term to more effectively avoid mistakes in the future. Purchasing duration had only a statistically significant effect on the dimension of brand/origin. Purchases duration had no statistically significant impact on the dimensions of color/size.

\begin{tabular}{|c|c|c|c|c|}
\hline \multirow[b]{2}{*}{ Path } & \multicolumn{3}{|c|}{ Unstandardized coefficients } & \multirow{2}{*}{$\begin{array}{c}\text { Stand. coefficient } \\
\text { Correlation } \\
\text { coefficient (ß) }\end{array}$} \\
\hline & $\begin{array}{l}\text { Correlation } \\
\text { coefficient }\end{array}$ & $\begin{array}{c}\text { Standard } \\
\text { error }\end{array}$ & t-value & \\
\hline Purch. freq. $\leftarrow$ Person. self-suffic. & $0.168^{* *}$ & 0.056 & 2.989 & $0.205^{\star *}$ \\
\hline Purch. duration $\leftarrow$ Person. self-suffic. & -0.042 & 0.048 & -0.875 & -0.055 \\
\hline Brand/origin $\leftarrow$ Person. self-suffic. & $-0.076^{*}$ & 0.037 & -2.053 & $-0.156^{*}$ \\
\hline Color/size $\leftarrow$ Person. self-suffic. & -0.040 & 0.051 & -0.800 & -0.065 \\
\hline Purch. duration $\leftarrow$ Purch. freq. & $0.295^{\star * *}$ & 0.056 & 5.318 & $0.319^{* * *}$ \\
\hline Brand/origin $\leftarrow$ Purch. freq. & $0.137^{\star *}$ & 0.047 & 2.941 & $0.230^{* *}$ \\
\hline Color/size $\leftarrow$ Purch. freq. & $0.230^{\star * *}$ & 0.063 & 3.662 & $0.303^{\star * *}$ \\
\hline Brand/origin $\leftarrow$ Purch. duration & $0.245^{\star * *}$ & 0.055 & 4.422 & $0.381^{\star * *}$ \\
\hline Color/size $\leftarrow$ Purch. duration & -0.030 & 0.070 & -0.429 & -0.036 \\
\hline Price level of $P P Q$ prod. $\leftarrow$ Brand/origin & $0.604^{* * *}$ & 0.112 & 5.413 & $0.493^{* * *}$ \\
\hline Share of domest. prod. $\leftarrow$ Brand/origin & $1.045^{\star * *}$ & 0.257 & 4.071 & $0.459^{* * *}$ \\
\hline Share of veg. versus fruit $\leftarrow$ Brand/origin & 0.291 & 0.213 & 1.369 & 0.130 \\
\hline Price level of PPQ prod. $\leftarrow$ Color/size & 0.023 & 0.076 & 0.302 & 0.024 \\
\hline Share of domest. prod. $\leftarrow$ Color/size & -0.278 & 0.160 & -1.740 & -0.155 \\
\hline Share of veg. versus fruit $\leftarrow$ Color/size & 0.113 & 0.169 & 0.665 & 0.064 \\
\hline Share of domest. prod. $\leftarrow$ Price level of PPQ prod. & 0.193 & 0.163 & 1.187 & 0.104 \\
\hline Share of domest. prod. $\leftarrow$ Share of veg. versus fruit & $0.258^{\star * *}$ & 0.060 & 4.270 & $0.254^{* * *}$ \\
\hline
\end{tabular}

TABLE 4. Path analysis of impacts of dimensions and endogenous variables.

Notes: PPQ prod. - Purchased perceived quality products; ${ }^{* * *}$ significant at $p<0.001$; ${ }^{* *}$ significant at $p<0.01$; ${ }^{*}$ significant at $p<0.05$.

The arrows $(\leftarrow)$ indicate the paths directions. 
Buyers, who highly valued the dimension of brand/ origin, had statistically, significantly, purchased perceived quality products that were in higher price regions. When buyers highly valued the dimension of brand/origin, that had a statistically significant positive effect on the share of purchased domestic products. Therefore, the domestic producers should also supply more information (e.g., specific information about the region and producer, production specifics, valuable nutrients, effect on health, and well-being) with their premium and non-premium products, because of the positive impact of the dimension of brand/origin. The price level of purchased perceived quality products had a positive statistically insignificant effect on the share of purchased domestic products (standardized correlation coefficient was 0.104). The last stated is good news for the domestic producers of vegetables and fruits, because buyers' attitude towards the purchased share of domestic products doesn't fall when the price level of purchased perceived quality products increases. The share of purchased vegetables versus fruits had a statistically significant positive effect on the share of purchased domestic products. So, those buyers who are purchasing more vegetables than fruits, purchase more domestic than foreign products (those who predominantly buy vegetables, buy more domestic products than those who predominantly buy fruits).

\section{Effects of control variables}

In Table 5, the statistically significant effects of demographic variables as control variables in the SEM model are presented. Also, the combinations of statistically significant covariances between the self-sufficiency from one's own garden or field and the demographic variables, are presented in Table 5. The following control variables were used: gender, age, education level, household income, and household size.

Gender had a statistically significant positive effect on the dimension of color/size (Table 5 ; men $=0$, women $=1$; with increasing values of the dimensions of color/size, the share of women versus men increased). The last stated was expected because of the larger gender differences between the means of factor scores of the dimension of color/size compared to the dimension of brand/origin (Figure 3). Composite factor scores were created with data imputation in AMOS and exported into SPSS.

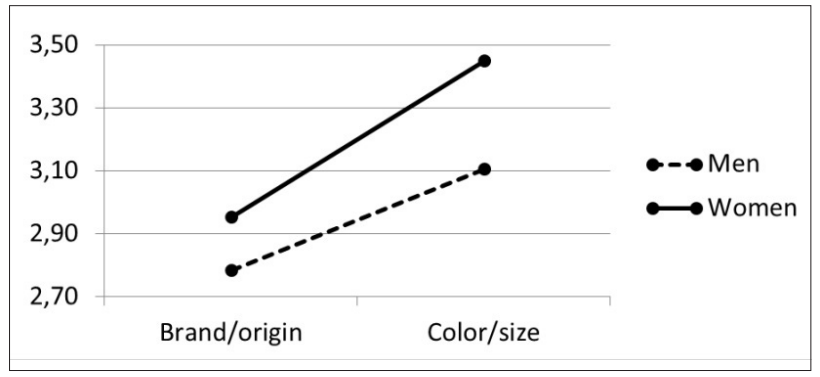

FIGURE 3. Means of factor scores of dimensions by gender.

Household income, on the one hand, had a positive, statistically significant effect on the price level of perceived quality (very good) products, and the household size, on the other hand, had a negative, statistically significant effect on the price level of perceived quality products. Purchased products of people who have more money to spend, which are, in their minds, perceived as very good products, fall in higher price ranges. Purchased products of larger households, which are, in their minds, perceived as very good products, fall in lower price ranges.

Households with higher incomes have shorter purchases durations and purchase higher price-level-perceived quality products. Household income had a negative statistically significant effect on the share of domestic products, while household size had a positive statistically significant effect on the share of domestic products. Those with higher incomes buy larger portions of foreign products, and those with lower incomes tend to buy more domestic products. Also, those larger households buy more domestic products. The last one is also encouraging information, because large households consume more food. Gender, age, and education level, on the other hand, had no statistically significant effect on the share of domestic products.

Age and level of education had a statistically significant positive effect on purchasing duration. Older people are slower in their purchasing process, and higher educated ones are looking for more information or have more specific purchasing goals, and that adds to the time it takes them to stop at the vegetable and fruit department of a grocery store.

TABLE 5. Significant effects and significant covariances of control variables.

\begin{tabular}{lcccc}
\hline & \multicolumn{2}{c}{ Unstandardized coefficients } & Stand. coefficient \\
\cline { 2 - 5 } Path & $\begin{array}{c}\text { Correlation } \\
\text { coefficient }\end{array}$ & $\begin{array}{c}\text { Standard } \\
\text { error }\end{array}$ & t-value & $\begin{array}{c}\text { Correlation } \\
\text { coefficient }(ß)\end{array}$ \\
\hline Color/size $\leftarrow$ Gender & $0.286^{*}$ & 0.133 & 2.144 & $0.163^{*}$ \\
Purch. duration $\leftarrow$ Age & $0.121^{*}$ & 0.050 & 2.445 & $0.150^{*}$ \\
Purch. duration $\leftarrow$ Education & $0.139^{* * *}$ & 0.039 & 3.529 & $0.253^{* * *}$ \\
Price level of PPQ prod. $\leftarrow$ Hous. incom. & $0.076^{* *}$ & 0.028 & 2.745 & $0.210^{* *}$ \\
Share of domest. prod. $\leftarrow$ Hous. incom. & $-0.161^{* *}$ & 0.057 & -2.817 & $-0.239^{* *}$ \\
Price level of PPQ prod. $\leftarrow$ Hous. size & $-0.130^{* *}$ & 0.036 & -3.592 & $-0.208^{* * *}$ \\
Share of domest. prod. $\leftarrow$ Hous. size & $0.193^{*}$ & 0.076 & 2.550 & $0.167^{*}$ \\
\hline Covariance & & & -2.109 & $-0.130^{*}$ \\
Person. self-suffic. $\leftrightarrow$ Gender & $-0.090^{*}$ & 0.043 & 3.717 & $0.243^{* * *}$ \\
Person. self-suffic. $\leftrightarrow$ Age & $0.443^{* * *}$ & 0.119 & -4.023 & $-0.247^{* * *}$ \\
Person. self-suffic. $\leftrightarrow$ Household size & $-0.463^{* *}$ & 0.115 & & \\
\hline
\end{tabular}

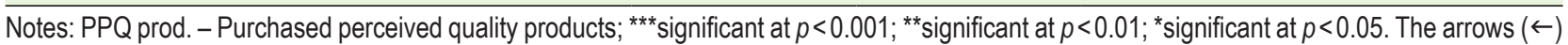
indicate the paths directions. Covariance $(\leftrightarrow)$. 
Between gender $($ men $=0$, women $=1)$ and the level of self-sufficiency from one's own garden, there was a significant negative covariance. Men in this research therefore had a higher self-sufficiency from one's own garden or field, than women. Between age and the level of self-sufficiency from one's own garden or field, there was a significant positive covariance. Also, between household size and the level of self-sufficiency from one's own garden, there was a significant positive covariance. Older people are the ones who in a higher percentage grew up on farms that had their own gardens and fields. Younger people often do not have the time to possess their own garden. The same could apply for larger families who need more time for household duties, and do not have the time to grow sufficient amounts of food for so many people.

\section{Conclusion}

Possible implications of this study are the following suggestions for producers of vegetables and fruits and retailers, with the goals, to improve their sales and profits.

Brand/origin and color/size were identified as the buyers' dimensions of a theoretical formative latent construct of the purchasing decision quality of vegetables, fruits, or both, at grocery stores in Slovenia. The identified dimension (brand, origin, packaging, nutrition) in this research is very similar to the dimension (brand, origin, packaging) in Hsu et al. (2017) research for the city of Taipei. The advice to producers is to create their own brands or extensively strengthen the existing ones. The small producers could for start create a brand name and logo with no further investments in marketing campaigns to make them for buyers more recognizable at their next purchase. The producers should also actively encourage the retailers to display their brands, with additional short information about the specifics of the production process and included nutrients. The quality of packaging that expands the product's life and ensures nice colors and freshness is also a future task for the domestic producers and suppliers who need to find cost-acceptable and time-efficient quality packaging solutions. The results of this research suggest that domestic producers of vegetables and fruits should not only have the courage to produce quality products in higher price regions, but also the wisdom to correctly choose what could be commercially successful. If the producers choose to produce vegetable products, there is possibly a slightly greater chance of success, because buyers who prevalently buy vegetables do have a larger share of purchased domestic products.

The main focus of the domestic producers should still be price affordable quality products, because larger households and households with lower incomes are the ones who are prevalently purchasing domestic products. The demographic data of the survey indicates that smaller households are becoming more prevalent and will gain more and more importance in the future. It was also proven that on the one hand, purchasing of high price-level perceived quality products still remains a domain of more wealthy households. But on the other hand, a good product can probably be interesting nowadays for almost everybody if it has the power to impress.

It was expected that color and size of vegetables and fruits are important, but this research proved that purchasing frequency has a significant positive effect on it. So, those who value more color and size do purchase more frequently, because color and size is so important to them. Domestic producers should be fully aware that there are buyers who are prepared to purchase more frequently. The buyers are, because of the high purchasing frequency, spending additional traveling time and transport costs to get what they really want. If there are products out there that are better looking, then the domestic producers should adapt quickly to that situation.

The retailers or suppliers could create brands to unite the products of domestic producers who are too small to have their own brands displayed in grocery stores. Retailers should also work more strongly on the goal to display domestic brands, at least, in black and white versions, especially for the unpackaged products in bulk. The display of domestic brands could easily be solved with solutions that include proper task organization, informatization, and cooperation among producers, suppliers, and retailers. E.g., a retailer would incorporate into the information system, a digital list of producers and suppliers with their brand logos which would instantly print out with the price tag and included information that will be displayed in a grocery store. A brand is a simple tool for easy and fast recognition of products. To boost sales of domestic products, retailers should also focus their ads on family themes, because larger households with lower incomes are those who predominantly purchase domestic vegetables and fruits. Women-oriented ads should also be pursued, because it was proven that they are more demanding when it comes to color and size of the products. Women in this survey proved to be more delicate and sophisticated when it comes to vegetables and fruits.

Older and higher educated buyers are more often searching for smart and useful information about the products that are offered in a grocery store, because they have significantly longer purchase durations.

The good news for the producers and retailers is that the level of personal self-sufficiency from one's own garden or field has an unexpected significant positive effect on purchasing frequency. So those who have a high self-sufficiency also purchase more frequently. Thus, it is possible for retailers with proper products to also convince those buyers who have their own gardens and fields. Younger buyers have, on average, a low or non-existent level of personal self-sufficiency from their own garden, and are a perspective group for future sales growth of vegetables and fruits.

This research did not contain the following relation: those who frequently purchase more vegetables, fruits, or both at grocery stores, also purchase larger quantities of them. For similar future research models, it is advisable to additionally incorporate the variables of quantity and spent money for purchasing vegetables, fruits, or both at grocery stores. The limitations of this study are also urban vs. non-urban differences, regional differences and fairly small sample size. The research model is also newly developed and there exists no similar model we could compare it to.

\section{References}

Calvo-Porral, C., and Levy-Mangin, J.P. (2016). Specialty food retailing: The role of purchasing frequency and determinants of customer satisfaction and loyalty. Brit. Food J. 118(11), 2798-2814. https://doi.org/10.1108/BFJ-03-2016-0100.

Cohen, J. (1992). A power primer. Psychol. Bull. 112(1), 155-159. https://doi.org/10.1037/0033-2909.112.1.155.

Comrey, A., and Lee, H. (1992). A first course in factor analysis (New York, NY: Hillsdale, Erlbaum).

Durian, J.C., and Tucci, L. (2013). Developing marketing strategies to increase vegetable consumption. J. of Cons. Mark. 30(5), 427-435. https://doi.org/10.1108/JCM-02-2013-0468. 
Fornell, C., and Larcher, D.F. (1981). Evaluating structural equation models with unobservable variables and measurement error. J. Mark. Res. 18(1), 39-50. https://doi.org/10.1177/002224378101800104.

Gao, Z., House, L.O., Gmitter, F.G. Jr., Valim, M.F., Plotto, A., and Baldwin, E.A. (2011). Consumer preferences for fresh citrus: impacts of demographics and behavioural characteristics. Int. Food Agribus. Manag. Rev. 14(1), 23-40.

Gao, Z., Wong, S.S., House, L.A., and Spreen, T.H. (2014). French consumer perception, preference of, and willingness to pay for fresh fruit based on country of origin. Brit. Food J. 116(5), 805-820. https://doi.org/10.1108/BFJ-12-2012-0303.

Grunert, K.G. (2005). Food quality and safety: consumer perception and demand. Eur. Rev. Agric. Econ. 32(3), 369-391. https://doi. org/10.1093/eurrag/jbi011.

Hinton, P.R., Brownlow, C., McMurray, I., and Cozens, B. (2004). SPSS Explained (London, UK, and New York, USA: Routledge, Taylor \& Francis Group).

Hsu, J.L., Shieu, C.W., and Hung, K.J.-R. (2017). Information used in food shoppers vegetable purchasing decisions in Chinese societies. Brit. Food J. 119(7), 1487-1494. https://doi.org/10.1108/BFJ-062016-0286.

Jackson, D.L., Gillaspy, J.A., and Purc-Stephenson, R. (2009). Reporting practices in confirmatory factor analysis: An overview and some recommendations. Psychol. Methods 14, 6-23. https:// doi.org/10.1037/a0014694.

Kline, R.B. (2011). Methodology in the Social Sciences. Principles and Practice of Structural Equation Modeling ( $3^{\text {rd }}$ edn.) (New York, NY, US: Guilford Press).

Kline, R.B. (2012). Assumptions of structural equation modeling. In Handbook of Structural Equation Modeling, R. Hoyle, ed. (New York, USA: Guilford Press), p. 111-125.

Lloret, S., Ferreres, A., Hernandez, A., and Tomas, I. (2017). The exploratory factor analysis of items: Guided analysis based on empirical data and software. Anales de Psicología 33, 417-432. https://doi.org/10.6018/analesps.33.2.270211.

Louangrath, M.M. (2014). Can R-square of 0.15 of a full model in SEM be acceptable? (Bangkok University, International College). https:// www.researchgate.net/post/Can_R_Square_of_15_of_a_full_model_ in_SEM_be_acceptable.

Malhotra, N.K., and Dash, S. (2011). Marketing Research: An Applied Orientation (London, UK: Pearson Publishing).

Olstad, D.L., Crawford, D.A., Abbott, G., McNaughton, S.A., Le, H.N.D., Mhurchu, C.N., Pollard, C., and Ball, K. (2017). The impact of financial incentives on participants' food purchasing patterns in a supermarket-based randomized controlled trial. Int. J. Behav. Nutr. Phys. Act. 14(115), 1-7. https://doi.org/10.1186/s12966-0170573-0.

Peneau, S., Hoehn, E., Roth, H.R., Escher, F., and Nuessly, J.A. (2006). Importance of consumer perception of freshness of apples. Food Qual. Pref. 17(1-2), 9-19. https://doi.org/10.1016/j. foodqual.2005.05.002.

Peneau, S., Linke, A., Escher, F., and Nuessly, J. (2009). Freshness of fruits and vegetables: Consumer language and perception. Brit. Food. J. 111(3), 243-256. https://doi.org/10.1108/00070700910941453.

Poole, N., and Baron, L. (1996). Consumer awareness of citrus fruit attributes. Brit. Food J. 98(1), 23-28. https://doi. org/10.1108/00070709610111296.

Qing, P., Lobo, A., and Chongguang, L. (2012). The impact of lifestyle and ethnocentrism on consumers' purchase intentions of fresh fruit in China. J. Consum. Mark. 29(1), 43-51. https://doi. org/10.1108/07363761211193037.
Ragaert, P., Verbeke, W., Devlieghere, F., and Debevere, J. (2004). Consumer perception and choice of minimally processed vegetables and packaged fruits. Food Qual. Pref. 15(3), 43-52. https://doi. org/10.1016/S0950-3293(03)00066-1.

Ringle, C.M., Wende, S., and Becker, J.-M. (2015). SmartPLS 3. http:// www.smartpls.com.

Rozin, P., Fischler, C., Imada, S., Sarubin, A., and Wrzesniewski, A. (1999). Attitudes to food and the role of food in life in the USA, Japan, Flemish Belgium and France: Possible implication for the diethealth debate. Appetite 33(2), 163-180. https://doi.org/10.1006/ appe.1999.0244.

Saucede, F., Fenneteau, H., and Cordon, J.M. (2014). Department upkeep and shrinkage control: Two key variables in optimizing the performance of fruit and vegetable departments. Int. J. Retail Distrib. Manag. 42(8), 733-758. https://doi.org/10.1108/ IJRDM-02-2013-0036.

Streiner, D.L. (1994). Figuring out factors: the use and misuse of factor analysis. Can. J. of Psych. 39(3), 135-140. https://doi. org/10.1177/070674379403900303.

Thornton, L.E., Pearce, J.R., Macdonald, L., Lamb, K.E., and Ellaway, A. (2012). Does the choice of neighborhood supermarket access measure influence associations with individual-level fruit and vegetable consumption? A case study from Glasgow. Int. J. Health Geogr. 11(29), 1-12. https://doi.org/10.1186/1476-072X-11-29.

Waterlander, W.E., Steenhuis, I.H.M., de Boer, M.R., Schuit, A.J., and Seidell, J.C. (2012). The effects of a $25 \%$ discount on fruits and vegetables: Results of a randomized trial in a three-dimensional web-based supermarket. Int. J. Behav. Nutr. Phys. Activity 9(11), 1-12. https://doi.org/10.1186/1479-5868-9-11.

Received: Oct. 12, 2018

Accepted: Oct. 18, 2019

Address of authors:

Damjan Grusovnik and Crtomir Rozman*

Department of Agricultural Economics, Faculty of Agriculture and Life Sciences, University of Maribor,

Pivola 10, 2311 Hoce, Slovenia

* Corresponding author; E-mail: crt.rozman@um.si

Tel.: +38626130863 